\title{
Effect of the mechanical activation on size reduction of crystalline acetaminophen drug particles
}

This article was published in the following Dove Press journal:

International Journal of Nanomedicine

7 December 2009

Number of times this article has been viewed

\author{
Esmaeil Biazar' \\ Ali Beitollahi ${ }^{2}$ \\ S Mehdi Rezayat ${ }^{3}$ \\ Tahmineh Forati ${ }^{4}$ \\ Azadeh Asefnejad ${ }^{4}$ \\ Mehdi Rahimi ${ }^{4}$ \\ Reza Zeinali ${ }^{4}$ \\ Mahmoud Ardeshir ${ }^{4}$ \\ Farhad Hatamjafari' \\ Ali Sahebalzamani ${ }^{4}$ \\ Majid Heidari ${ }^{4}$ \\ 'Chemistry Department, Islamic \\ Azad University, Tonekabon \\ Branch, Mazandaran, Iran; ${ }^{2}$ Material \\ Department, Iran University of \\ Science and Technology, Tehran, \\ Iran; ${ }^{3}$ Department of Pharmacology, \\ School of Medicine, Tehran University \\ of Medical Sciences, Tehran, Iran; \\ ${ }^{4}$ Biomedicall Department, Islamic \\ Azad University, Science and Research \\ Branch, Tehran, Iran
}

Correspondence: Esmaeil Biazar Chemistry Department, Islamic Azad University, Tonekabon Branch, Tehran, Iran $\mathrm{Tel}+989119920858$

Fax +98 2I 44474319

Email e.biazar@srbiau.ac.ir

\begin{abstract}
The decrease in particle size may offer new properties to drugs. In this study, we investigated the size reduction influence of the acetaminophen $\left(\mathrm{C}_{8} \mathrm{H}_{9} \mathrm{O}_{2} \mathrm{~N}\right)$ particles by mechanical activation using a dry ball mill. The activated samples with the average size of $1 \mu \mathrm{m}$ were then investigated in different time periods with the infrared (IR), inductively coupled plasma (ICP), atomic force microscopy (AFM), and X-ray diffraction (XRD) methods. The results of the IR and XRD images showed no change in the drug structure after the mechanical activation of all samples. With the peak height at full width at half maximum from XRD and the Scherrer equation, the size of the activated crystallite samples illustrated that the AFM images were in sound agreement with the Scherrer equation. According to the peaks of the AFM images, the average size of the particles in 30 hours of activation was $24 \mathrm{~nm}$ with a normal particle distribution. The ICP analysis demonstrated the presence of tungsten carbide particle impurities after activation from the powder sample impacting with the ball and jar. The greatest reduction in size was after milling for 30 hours.
\end{abstract}

Keywords: acetaminophen, mechanical activation, structure investigation, nanoparticles, ball mill

\section{Introduction}

Nanotechnology includes the study, control, and material construction of particles of $10^{-9} \mathrm{~m}$. The significant impacts of nanotechnology have received great attention in various fields such as material science, medicine, electronics, optics, electrochemistry, and electromagnetism. The generation of nanoparticle drugs has created new perspectives for pharmacology, but the successful development of this technology depends on exploring their properties completely. High-pressure homogenization and supercritical fluid processing are the technologies that are used currently or are being developed for nanoparticle generation. ${ }^{1}$ Using nanodrug particles has opened up a new world for pharmacology. For this science to become more practical we have to discover the characteristics of such nanoparticles. ${ }^{2,3}$ One method for the preparation of micro- and nanoparticles is mechanical activation. The actual process of mechanical alloying starts with mixing the component powders in the correct proportion and loading the mixture into the grinding mill along with the grinding medium - generally steel balls. The mixture is then milled for the desired length of time until a steady state is reached, ie when the composition of the powder particles are the same as the proportion of the components of the original mixture. The milled powder is then consolidated into a bulk shape and heat treated to obtain the desired microstructure and properties. Thus the important components of the mechanical alloying process were the raw materials,

submit your manuscript | www.dovepress.con 
the mill, and the process variables. Nevertheless particle size reduction, which increases the contact surface area between particles, is a direct consequence of milling. As the energy of the system is increases there is a concomitant decrease in mullitization temperatures. ${ }^{4}$ The amount of energy required to affect fracture is dependent on the hardness and particle size of the material being milled and the type of stress applied. According to fracture theory, the hardness of a material increases as its particle size decreases, as a consequence the milling of finer materials requires more energy and therefore higher impact speeds. ${ }^{5,6}$ Mechanical activation has become a phenomenon of general significance in pharmaceutics. Hüttenrauch and colleagues described the extent of activation induced by relevant processes. ${ }^{7}$ Haüsler and colleagues demonstrated the influence of mechanical activation on the physical stability of salbutamol sulphate. ${ }^{8}$

Acetaminophen plays a key role in reducing the effects of pain and fever and chemical methods are considered to be the only means for producing this type of drug. ${ }^{9-11}$ In chemical preparations of Acetaminophen particle size has been shown to follow a normal distribution with a mean particle size of $100 \mu \mathrm{m} .{ }^{12-14}$

The new size reduction method for homogenizing acetaminophen particles is the crystallization product of $\mathrm{CO}_{2}$ compact fluids which is used for the direct production of nanocrystalline or microsize particles. Acetaminophen production with $\mathrm{CO}_{2}$ compact fluids provides high uniformity and homogenization, however, this method is very expensive. ${ }^{9-14}$ The effect of mechanical activation on acetaminophen powders and their physicochemical properties are explored in this study.

\section{Materials and methods}

\section{Materials and instruments}

Pure acetaminophen powder with an average size of $1 \mu \mathrm{m}$ (estimated by X-ray diffraction [XRD] and scanning electron microscopy [SEM]) was purchased from Chemi Darou (Tehran, Iran). In addition, distilled water and ethanol were used. The equipment used in this work included: a digital balance with a $0.01 \mathrm{~g}$ sensitivity (Mettler-PM-4800; MettlerToledo, Columbus, OH, USA), an infrared (IR) analyzer INS $(\mathrm{KBr})$ and a ball mill (made from tungsten carbide, (WC)). A measure of the impurities, produced by the balls contacting the inside of the mill, and drug content, from the mechanical activation, was estimated using inductively coupled plasma (ICP The particle size distribution was measured using atomic force microscopy (AFM) (K-Alpha, 1:5405600 wave length and $2 \theta$ angle radiation).

\section{Methods}

Samples of $2 \mathrm{~g}$ or $4 \mathrm{~g}$ pure acetaminophen powder were poured into the grinding mill with the $\mathrm{WC}$ balls in a ratio 1:15 (w/w). They were then mechanically activated for varying periods of time $(15,30,55$, and 60 hours). All the samples for chemical analysis and structural investigations were prepared in this way.

\section{Results}

\section{The IR results}

IR analysis revealed that the structure of the acetaminophen powder in the activated samples remained the same, with no observable changes. Figure 1 illustrates the pure, un-milled, acetaminophen powder samples. In Figure 1A and 1B, the peaks at the following wavelengths represent specific functional groups contained in the acetaminophen molecule: at $3600 \mathrm{~cm}^{-1}$ the $-\mathrm{OH}$ groups; at $1200-1300 \mathrm{~cm}^{-1}$ were associated $\mathrm{C}=\mathrm{C}$ groups; $3000 \mathrm{~cm}^{-1}$ to the $\mathrm{N}-\mathrm{H}$ groups and at $2000 \mathrm{~cm}^{-1}$ to the $\mathrm{C}=\mathrm{O}$ groups. Finally, the $\mathrm{N}-\mathrm{H}$ bending vibration is seen at $500 \mathrm{~cm}^{-1}$ and the stretch - vibration groups at $1600-1400 \mathrm{~cm}^{-1}$ were attributed to the $\mathrm{C}=\mathrm{C}$ groups.

\section{The $X R D$ results}

For the XRD analysis four acetaminophen powder samples were tested, the normal un-milled sample together with the mechanically activated samples milled for 15,30, and 55 hours. The 15-hour mechanically activated sample and the normal un-milled sample demonstrated no specific variation in their structure. The remaining mechanically activated samples, those for 30 and 55 hours milling were investigated more thoroughly. Figure 2 represents the X-ray

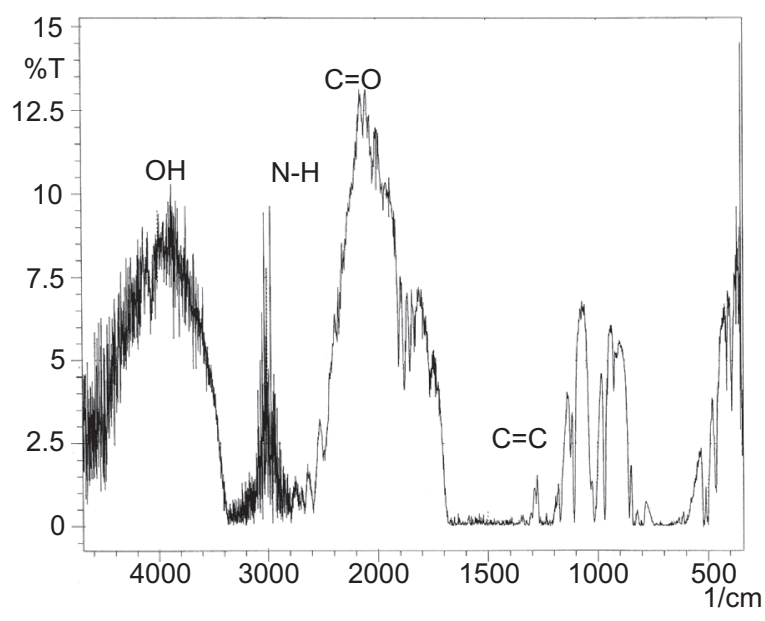

Figure I The infrared images of the acetaminophen powder samples produced by normal size samples and produced in 30 hours of mechanical activation powder samples. 


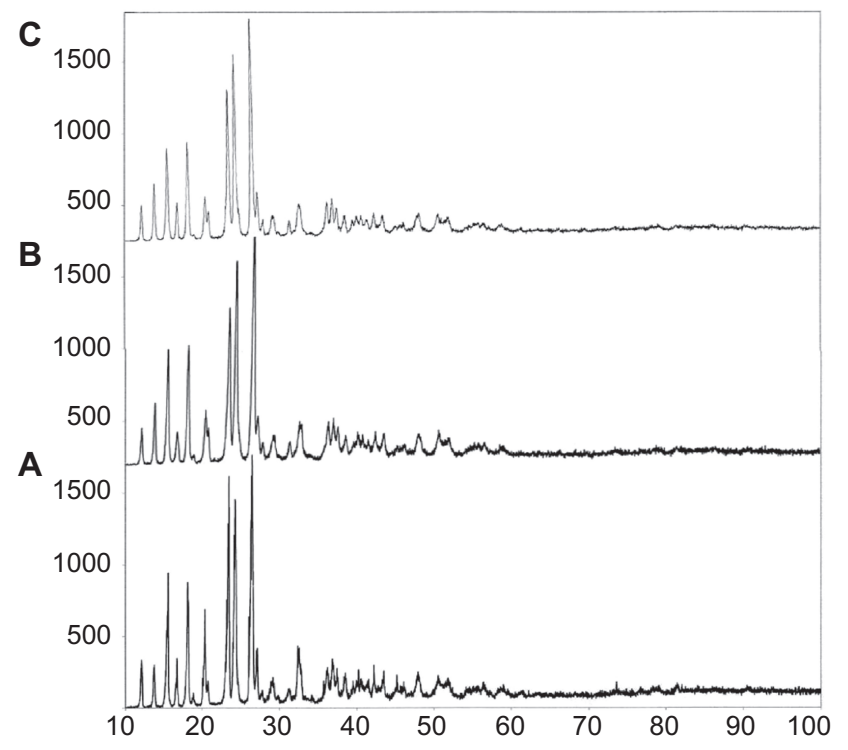

Figure 2 The X-ray diffraction peaks of the acetaminophen powder samples. A) Peaks of the normal size acetaminophen powder samples. B) Peaks of the reduced size acetaminophen powder samples for 30 hours of mechanical activation. C) Peaks of the reduced size acetaminophen powder samples for 55 hours of mechanical activation.

defraction spectra of the normal un-milled acetaminophen, (Figure 2A), the sample mechanically activated for 30 hours, (Figure 2B), and the mechanically activated sample for 55 hours, (Figure 2C).

The maximum $2 \theta$ peak was equal to $26^{\circ}$ and related to the $\left(2^{-} 21\right)$ and $\left(3^{-} 11\right)$ surfaces. The crystallite size of the three maximum peaks from right to left were associated with the (1-21), (2-20), (3-11) surfaces and was determined with the use of the Scherrer equation with the full-width at half-maximum (FWHM) values.

By activating FWHM, the related angle crystallite sizes can be determined with the Scherrer equation. Table 1 exhibits the FWHM, the $2 \theta$ angle and the mean particle size for the mechanically activated samples milled for 30 and 55 hours. The results are related to the three XRD maximum peak surfaces. However, FWHM cannot be accurately estimated because of the overlapping of the two peaks. The peak of surface (101) was estimated afterward.

Table I The FWHM, the angles, and the sizes of the activated powder samples in 30 and 55 hours

\begin{tabular}{lll}
\hline $\begin{array}{l}\text { Maximum peaks } \\
\text { properties }\end{array}$ & $\begin{array}{l}\text { 30-hour activated } \\
\text { samples }\end{array}$ & $\begin{array}{l}\text { 55-hour activated } \\
\text { samples }\end{array}$ \\
\hline FWHM & 0.3289 & 0.1555 \\
$2 \theta$ angle $(\mathrm{deg})$ & 16.57 & 16.57 \\
Size $(\mathrm{nm})$ & 24.4 & 51.6 \\
\hline
\end{tabular}

Abbreviation: FWHM, full width at half maximum.

\section{The AFM results}

The AFM images of the two drug samples (the 30-hour mechanically activated sample and the 55-hour mechanically activated sample) are given in Figure 3 and Figure 4. Scans of $5 \times 5 \mu \mathrm{m}$ and $20 \times 20 \mu \mathrm{m}$ determined the particle size distribution, growth, and the nature of the crystallites on mica surfaces. Figures 3B and 4B display the average size and the particle distribution for samples mechanically activated for 30 hours and 55 hours respectively. The uniform distribution,
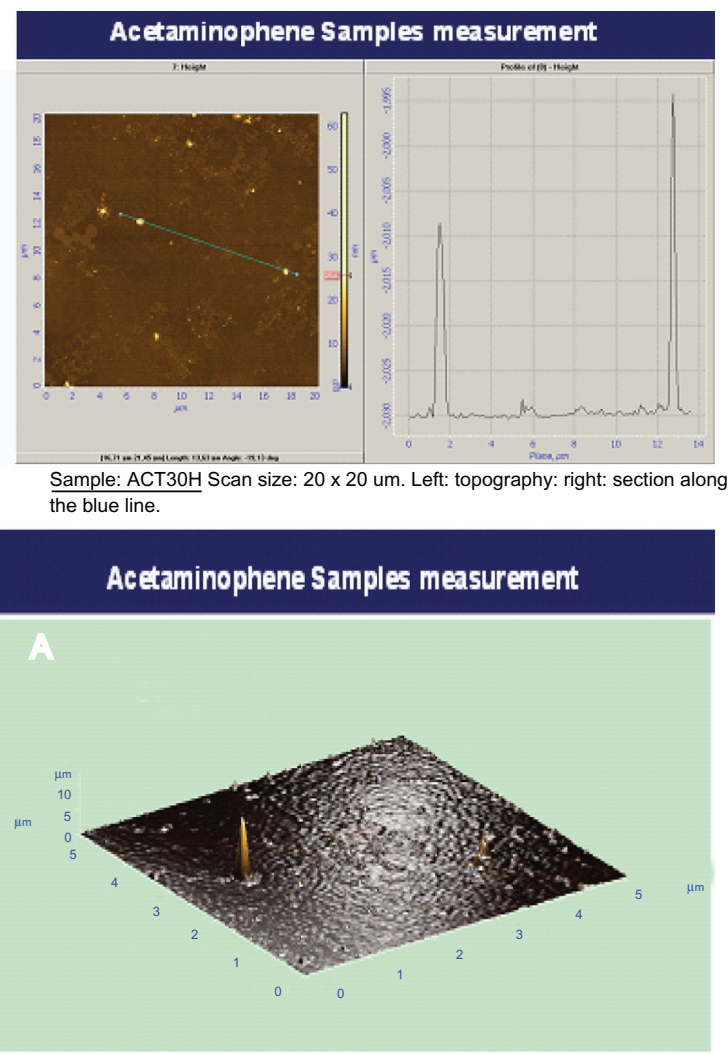

Sample: ACT30H Scan size: $5 \times 5$ um. 3D - view of the surface.

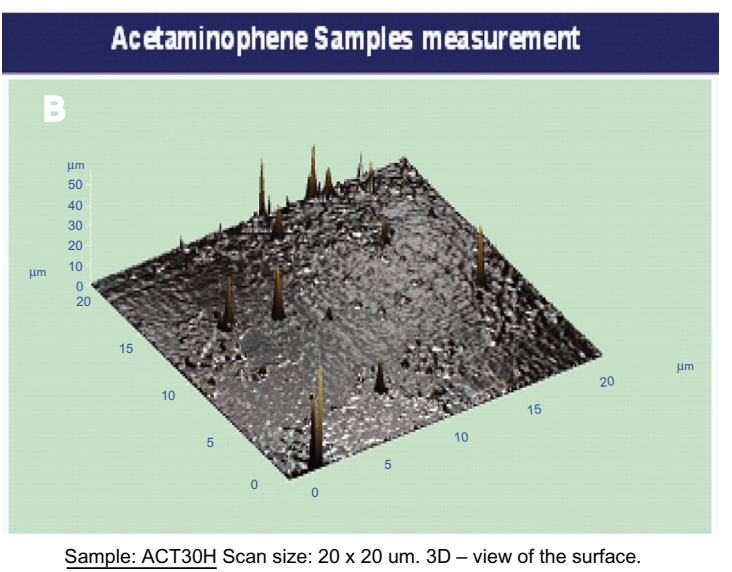

Figure 3 The topography and the average size distribution of the acetaminophenactivated particles in 30 hours with the scans of $20 \times 20 \mu \mathrm{m} \mathrm{A}$ ) and $5 \times 5 \mu \mathrm{m} \mathrm{B}$ ). 


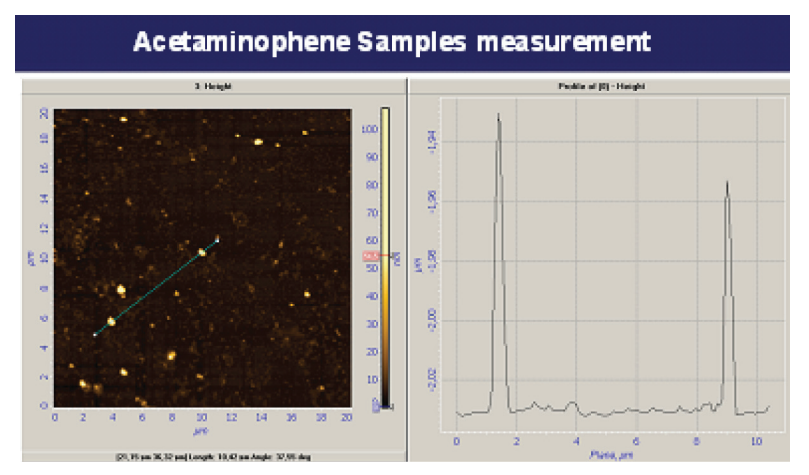

Sample: ACT55. Scan size: $20 \times 20$ um. Left: topography: right: section along the blue line.

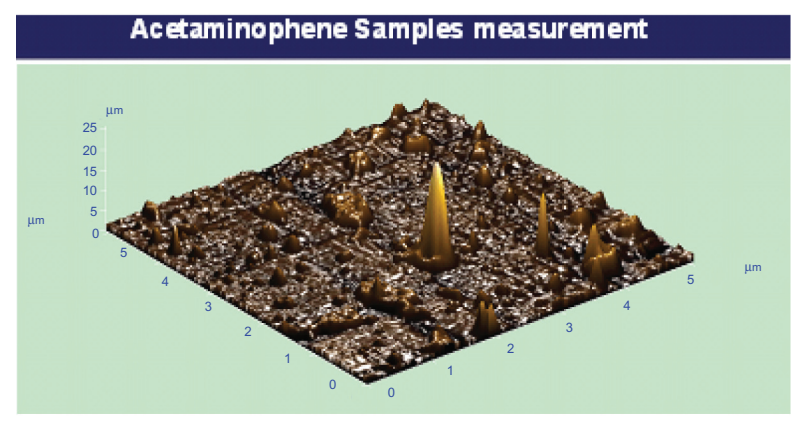

Sample: ACT55. Scan size: $5 \times 5$ um. 3D - view of the surface.

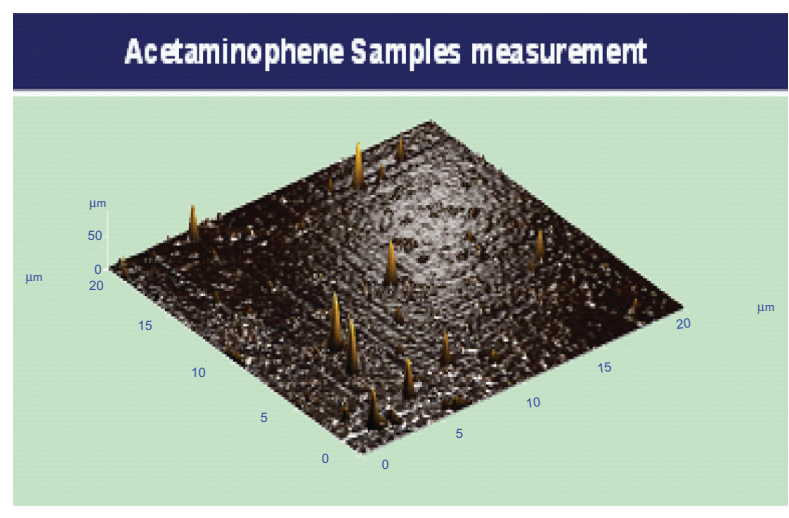

Sample: ACT55. Scan size: $20 \times 20$ um. 3D - view of the surface.

Figure 4 The topography and the average size distribution of the acetaminophenactivated particles in 55 hours with the scans of $20 \times 20 \mu \mathrm{m}(\mathbf{A})$ and $5 \times 5 \mu \mathrm{m}(\mathbf{B})$.

growth, and size of the crystallites were determined with $20 \times 20 \mu \mathrm{m}$ scans which are depicted in Figures $3 \mathrm{C}$ and $4 \mathrm{C}$ for samples mechanically activated for 30 hours and 55 hours respectively. The $20 \times 20 \mu \mathrm{m}$ scan was used to determine the mean size of the crystallites which we found to be $24 \mathrm{~nm}$ and

Table 2 The amount of tungsten in the drug for normal sample and the best sample with reduced size

\begin{tabular}{ll}
\hline Sample & $\begin{array}{l}\text { The amount of tungsten } \\
\text { in the drug }(\mathrm{g} / \mathrm{g})\end{array}$ \\
\hline Normal & - \\
30-hour activation & 0.0001 \\
\hline
\end{tabular}

Table 3 The percentage of impurity in the drug for normal sample and the best sample with reduced size

\begin{tabular}{ll}
\hline Sample & $\begin{array}{l}\text { The percentage of } \\
\text { impurity }(\mathbf{g})\end{array}$ \\
\hline Normal & $0.001 \%$ \\
30 -hour activation & $0.0013 \%$ \\
\hline
\end{tabular}

$54.6 \mathrm{~nm}$ for the samples mechanically activated for 30 hours and 55 hours respectively, this was in agreement with the XRD results. After 55 hours of mechanical activation their uniformities were lost.

\section{The ICP results}

The impurity of the drug with tungsten carbide resulted from the collision of the drug particles with the surfaces of the milling jar and balls. I Tables 2 and 3, show the nature of these impurities, the mass and percentage of WC in the drug sample for samples mechanically activated for 30 hours with maximum reduced size by ICP.

\section{Conclusion and discussion}

The IR images showed that there were no changes in the acetaminophen structure. The XRD peaks also confirmed that there were no phase changes in the reduced size samples after 15 and 30 hours of milling. The average crystallite size in the 30-hour mechanically activated samples, as compared to the normal un-milled and the 55-hour mechanically activated samples were demonstrably smaller. In the 55-hour mechanically activated samples, an enlargement in the particle size took place, ie an increase from $24 \mathrm{~nm}$ in samples milled for 30 hours to $54.6 \mathrm{~nm}$ for samples milled for 55 hours.

The AFM images displayed the same results with a higher resolution. The AFM images present the average size and the acetaminophen crystalline particle distribution in different scans. Regarding these images, the particle size of the 30-hour mechanically activated samples were decreased from the initial size (the normal un-milled samples) of $1,000 \mathrm{~nm}$ to $24 \mathrm{~nm}$. However, the particle size of the 55-hour mechanically activated samples were enlarged due to diffusion. Grain boundary diffusion during mechanical activation is the dominant phenomenon, because particle size reduction leads to the increase in the particle surface area grain boundary diffusion increases which leads to grain growth in nanocrystalline materials.

\section{Disclosures}

The authors report no conflicts of interest in this work. 


\section{References}

1. Chow GM. Nanostructured materials. In: Gan-Moog Chow GM, Noskova NI, editors. Nanostructured Materials Science and Technology. Heidelberg, Germany: Springer; 1998.

2. Rabinow BE. Nanosuspensions in drug delivery. Nat Rev Drug Discov. 2004;3:785-796.

3. Lee J. Drug nano-and microparticles processed into solid dosage forms: physical properties. J Pharm Sci. 2003;92(10):2057-2068.

4. Suryanarayana C. Mechanical alloying and milling. Prog Mater Sci. 2001;46:1-184.

5. Schlaug H, Einzelprobleme bei der Luftstrahlmahlung. Frankfurt, Germany: Vortr. Diskussionen Europäischen Symp. Zerkleinern, 1; 1962. p. 531-553.

6. Pahl MH. Zerkleinerungstechnik. 2. Fachbuchverlag Leipzig/Verlag TÜV, Rheinland: Auflage; 1991.

7. Hüttenrauch R, Fricke S, Zielke P. Mechanical activation of pharmaceutical systems. Pharm Res. 1985;2:302-306.

8. Hausler.

9. Brodka-Pfeiffer K, Langguth P, Grass P, Häusler H. Influence of mechanical activation on the physical stability of salbutamol sulphate. Eur J Pharm Biopharm. 2003;56:393-400.
10. Ventosa N, Sala S, Veciana J. DELOS process: A crystallization technique using compressed fluids. 1. Comparison to the gas crystallization methods. J Supercrit Fluids. 2003;26:33-45.

11. Sarkari M, Brown J, Chen X, Swinnea S, Williams RO 3rd, Johnston KP. Enhanced drug dissolution using evaporative precipitation into aqueous solution. Int J Pharm. 2002;243:17-31.

12. Hu J, Rogers TL, Brown J, Young T, Johnston KP, Williams RO 3rd. Improvement of dissolution rates of poorly water soluble APIs using novel spray freezing into liquid technology. Pharm Res. 2002;19:1278-1284.

13. Sweetman SC. Martindale: The complete drug reference. 34th ed. London, UK: Pharmaceutical Press; 2005.

14. Rinaki E, Valsami G, Macheras P. Quantitative biopharmaceutics classification system: The central role of dose/solubility ratio. Pharm Res. 2003;20:1917-1925.

15. Rustichelli C, Gamberini G, Ferioli V, Gamberini MC, Ficarra R, Tommasini S. Solid-state study of polymorphic drugs: carbamazepine. J Pharm Biomed Anal. 2000;23:41-54.
International Journal of Nanomedicine

\section{Publish your work in this journal}

The International Journal of Nanomedicine is an international, peerreviewed journal focusing on the application of nanotechnology in diagnostics, therapeutics, and drug delivery systems throughout the biomedical field. This journal is indexed on PubMed Central, MedLine, CAS, SciSearch $\AA$, Current Contents ${ }^{\circledR} /$ Clinical Medicine,

\section{Dovepress}

Journal Citation Reports/Science Edition, EMBase, Scopus and the Elsevier Bibliographic databases. The manuscript management system is completely online and includes a very quick and fair peer-review system, which is all easy to use. Visit http://www.dovepress.com/ testimonials.php to read real quotes from published authors. 